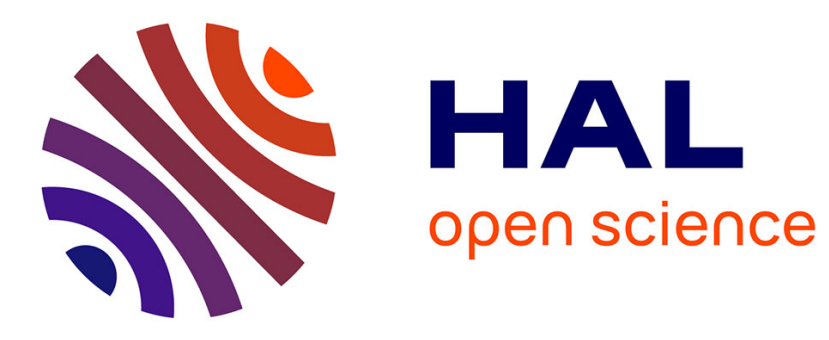

\title{
On the origin of deviatoric stresses in the lithosphere
}

\author{
Bai Wuming, C. Vigny, Y. Ricard, C. Froidevaux
}

\section{To cite this version:}

Bai Wuming, C. Vigny, Y. Ricard, C. Froidevaux. On the origin of deviatoric stresses in the lithosphere. Journal of Geophysical Research, 1992, 97 (B8), pp.11,729-11,737. 10.1029/91JB00292 . hal-02046597

\section{HAL Id: hal-02046597 \\ https://hal.science/hal-02046597}

Submitted on 3 Feb 2021

HAL is a multi-disciplinary open access archive for the deposit and dissemination of scientific research documents, whether they are published or not. The documents may come from teaching and research institutions in France or abroad, or from public or private research centers.
L'archive ouverte pluridisciplinaire HAL, est destinée au dépôt et à la diffusion de documents scientifiques de niveau recherche, publiés ou non, émanant des établissements d'enseignement et de recherche français ou étrangers, des laboratoires publics ou privés. 


\title{
On the Origin of Deviatoric Stresses in the Lithosphere
}

\author{
Bai Wuming, ${ }^{1}$ Cristophe Vigny, Yanick Ricard, and Claude Froidevaux \\ Département de Géophysique, Ecole Normale Supérieure, Paris, France
}

\begin{abstract}
Mantle circulation models capable of predicting satisfactory plate velocities and geoid are tested for their ability to generate adequate lithospheric stresses. The model Earth mantle is driven by mass heterogeneities defined by seismic tomography and slab distribution. Its surface is divided into 11 freely moving plates. The mantle circulation produces shear stresses at the base of each plate. These are used to compute a dynamical component of the lithospheric stresses which is added to another component induced by variations of the Moho depth inside the lithosphere itself. The extensional state of the continents caused by their thick crust is more than compensated by a compressional tendency related to their high seismic velocity roots, interpreted as dense roots. Strong upwellings beneath equatorial regions with geoid highs could also generate anomalous topography and extensional stresses. The long-w avelength stress pattern proposed by our models cannot easily be compared with available data: the internal loads are still poorly defined, the tested Earth model may be too simple, and the observations are unadequately distributed.
\end{abstract}

\section{INTRODUCTION}

Plate motion has led to the idea that a given lithospheric plate must be submitted to driving and resistive forces. In the absence of acceleration the net torque of these forces must vanish [Lliboutry, 1972; Forsyth and Uyeda, 1975; Richardson et al., 1979]. A well understood, but rather poorly named, driving force is the "ridge push" [McKenzie and Bowin, 1976]. It can be quantified exactly but is not really applied at the axis of the oceanic ridge. It is related to a distributed vertical stress caused by the weight of the ridge topography and the opposed buoyancy of its thermal root [Hager, 1978; Parsons and Richter, 1981; Fleitout and Froidevaux, 1983]. Oceanic plates are also driven by the pull transmitted by their subducting slabs plunging back into the Earth's mantle, particularly when this slab is old, i.e., dense enough [Vlaar and Wortel, 1976]. Here the quantification is somewhat difficult as the strong negative buoyancy of this cold slab is more or less balanced by the viscous drag which tends to oppose this penetration into the warmer and more ductile mantle. The net effect can be derived from seismological observations, indicating that the shallow portion of subducted slabs is usually in downdip extension [Isacks and Molnar, 1971]. This implies a net pull which is expected to vary with the age dependent thickness of the slab and with its converging velocity known from plate tectonics. Resistive stresses acting on a tectonic plate are expected along its transform fault edges and, on the average, at the base of the plate [Richardson et al., 1979]. With this class of models one can determine the relative magnitude of the driving and resistive forces by trial and error or by inversion. The criterion of selection consists of matching the observed orientations and signs of tectonic stresses. For instance, the strong N-S compression zone in the Indian Ocean has been successfully modeled on the basis of this approach [Cloetingh and Wortel, 1986].

\footnotetext{
${ }^{1}$ Permanently at Laboratory of Geophysics, Academia Sinica, Beijing, People's Republic of China.
}

Copyright 1992 by the American Geophysical Union.

Paper number 91JB00292.

$0148-0227 / 92 / 91 \mathrm{JB}-00292 \$ 05.00$
Intraplate sources of stress have been ignored in the above models based on static torque balances. They could be included without difficulty. They are connected with the existence of lateral density heterogeneities within the lithosphere, in particular with variations of crustal thickness and associated surface topographies [Artyushkov, 1973; Fleitout and Froidevaux, 1983]. The physics is the same as that which explains the "ridge push", but the structures are located inside the plate rather that near one of its edges. The most spectacular examples are the high plateaus like Tibet, the Altiplano, and the North American Cordillera, where extensional tectonics in the highlands is flanked by compressional activity in the Piedmonts and neighboring lowlands [Froidevaux and Isacks, 1984]. Of course, the stress pattern can also be perturbed by lateral variations of the mechanical strength of the lithospheric material, i.e., by the existence of harder and softer blocks inherited from the geological past [Vilotte et al., 1986]. It is important when not only the stress configuration but also the large ductile deformations are estimated. This remark applies to the case of Tertiary deformation in western North America, where the Colorado Plateau has been left isolated from neighboring Basin and Range structures. The preservation of its dense lithospheric root tends to maintain this plateau in relative compression.

Bending stresses are an important component of lithospheric stresses [e.g., Cloetingh et al., 1989]. However, this is only true at distances from the loading masses shorter than a few hundreds of kilometers. In this study these flexural stresses are neglected as the attention is focussed on longer wavelengths.

This study will consider an elastic lithosphere containing mass heterogeneities and being in mechanical contact with an actively convective mantle. The convection pattern is driven by internal loads located in both upper and lower mantle. These mass heterogeneities are defined on the basis of global seismic tomography models, which describe lateral variations in seismic velocities for the lowest degrees of spherical harmonics ( $l \leq 6$ or 8 ) [Dziewonski, 1984; Woodhouse and Dziewonski, 1984; Nataf et al., 1986]. In recent years these new data sets have been successfully used to predict the observed geoid and divergence of the plate tectonic velocities in the framework of a purely radial viscosity stratification [Hager et al., 1985; Forte and Peltier, 1987; Ricard 


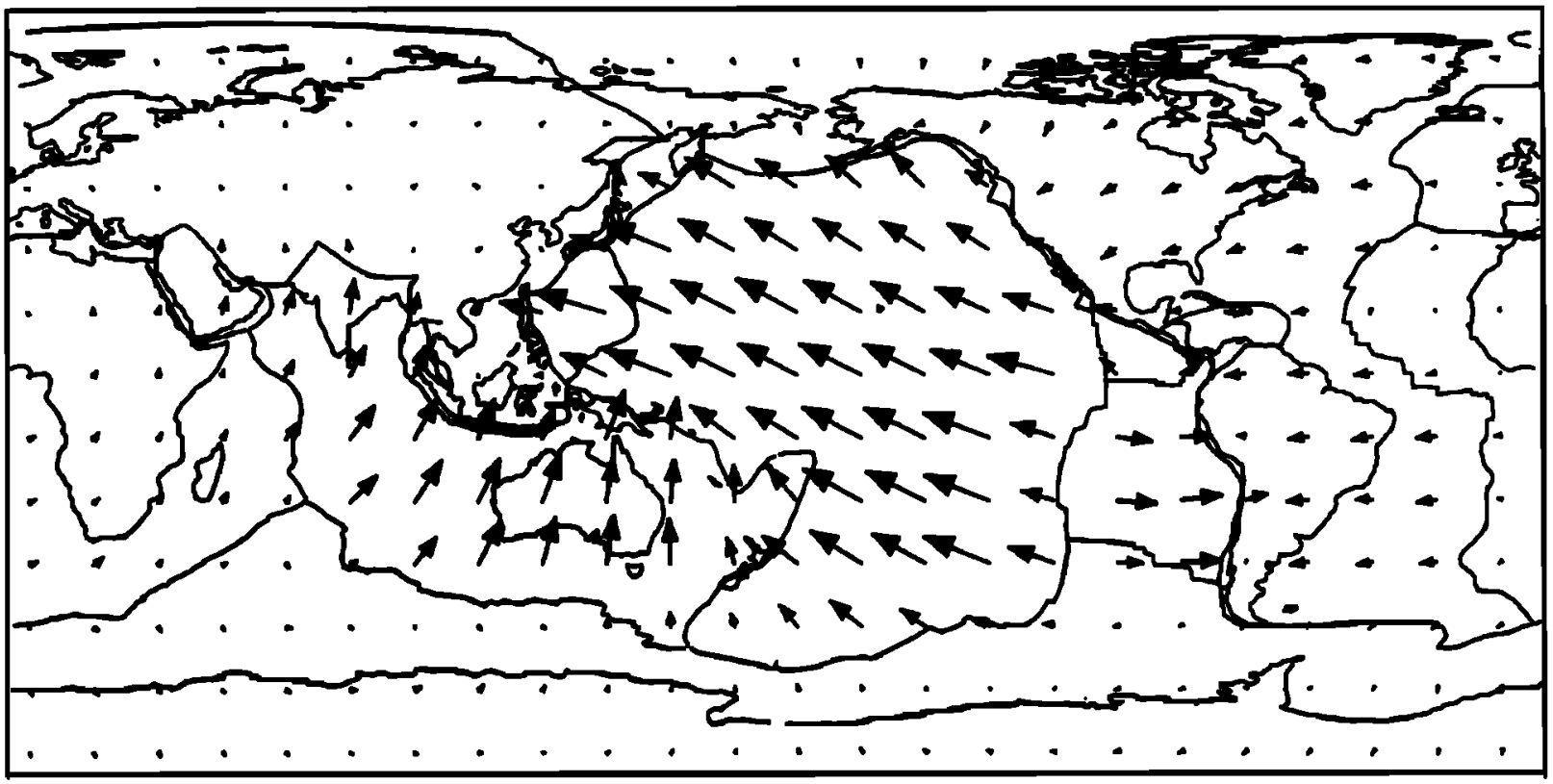

\section{Scale $10 \mathrm{~cm} / \mathrm{yr} \rightarrow$}

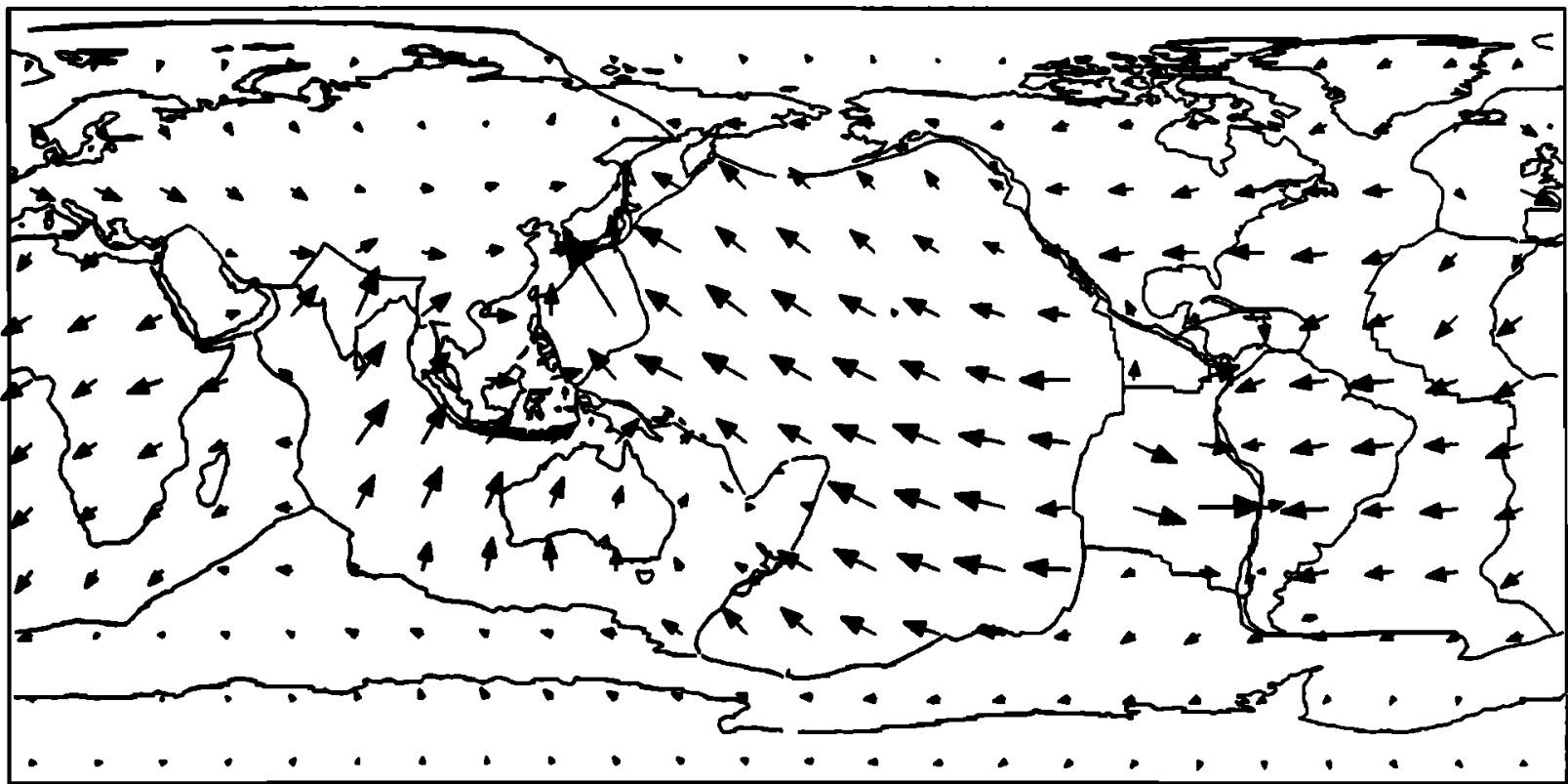

Fig. 1. Comparison between plate tectonic velocities (top map) and plate velocities computed on the basis of the dynamic mantle model with internal loads (bottom map). Both velocity patterns are filtered out for spherical harmonic degrees larger than $l=15$. They do not include a net rotation of the whole lithosphere, which is usually found in representations relative to the hot spots. This computed model will be called model $\mathrm{A}$ in the next section.

et al., 1989]. The most recent advance consisted of solving this forward problem of the deep mantle circulation for an Earth model with freely moving rigid surface plates corresponding to the 11 major plates of the Earth. These model plates are entirely driven by the mantle circulation, each plate moving in a direction which sets the torque of the shear stresses acting at its base to zero [Ricard and Vigny, 1989; Vigny et al., 1991]. Figure 1 reproduces the predicted and observed velocities. The match for the fast moving plates is amazingly good. However, noticeable discrepancies exist for this model for which no attempt was made to optimize the prediction. Earlier studies had indeed shown that dynamic models are sensitive to the chosen radial viscosity structure. Here a simple increase by a factor 50 was chosen at the interface between upper and lower mantle. Furthermore this interface is not a chemical barrier so that the mantle flow can go across it. We shall retain these simple characteristics in the present study. The main discrepancy seen in Figure 1 is the fact that the model African plate rotates in a clockwise rather than counterclockwise sense. This is 

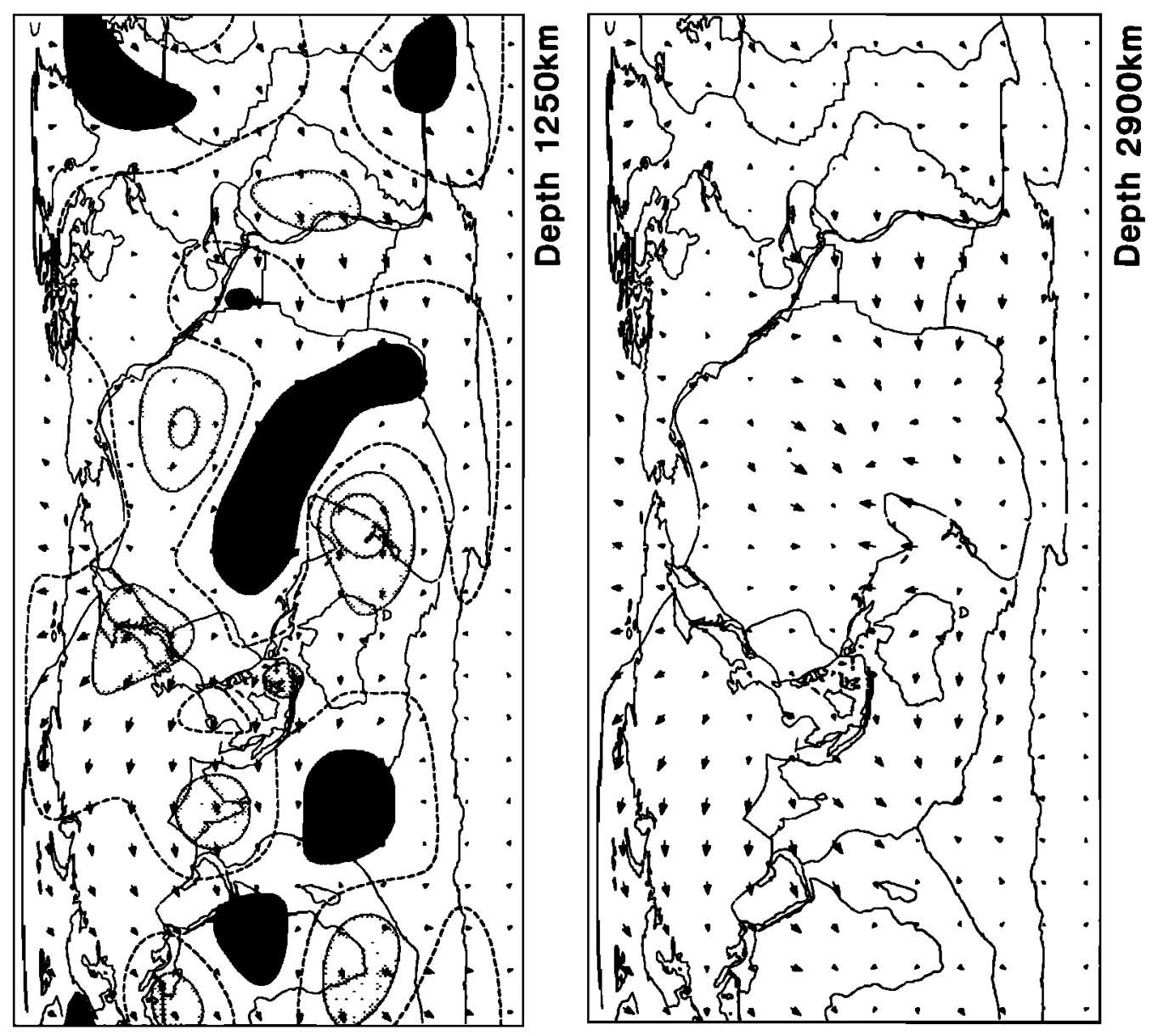

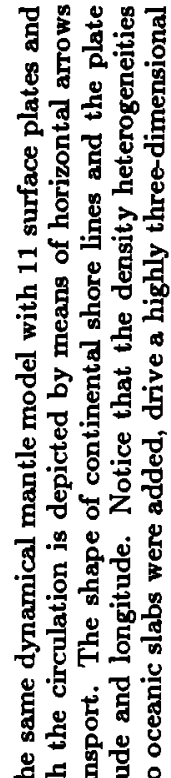
马

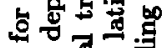

조경
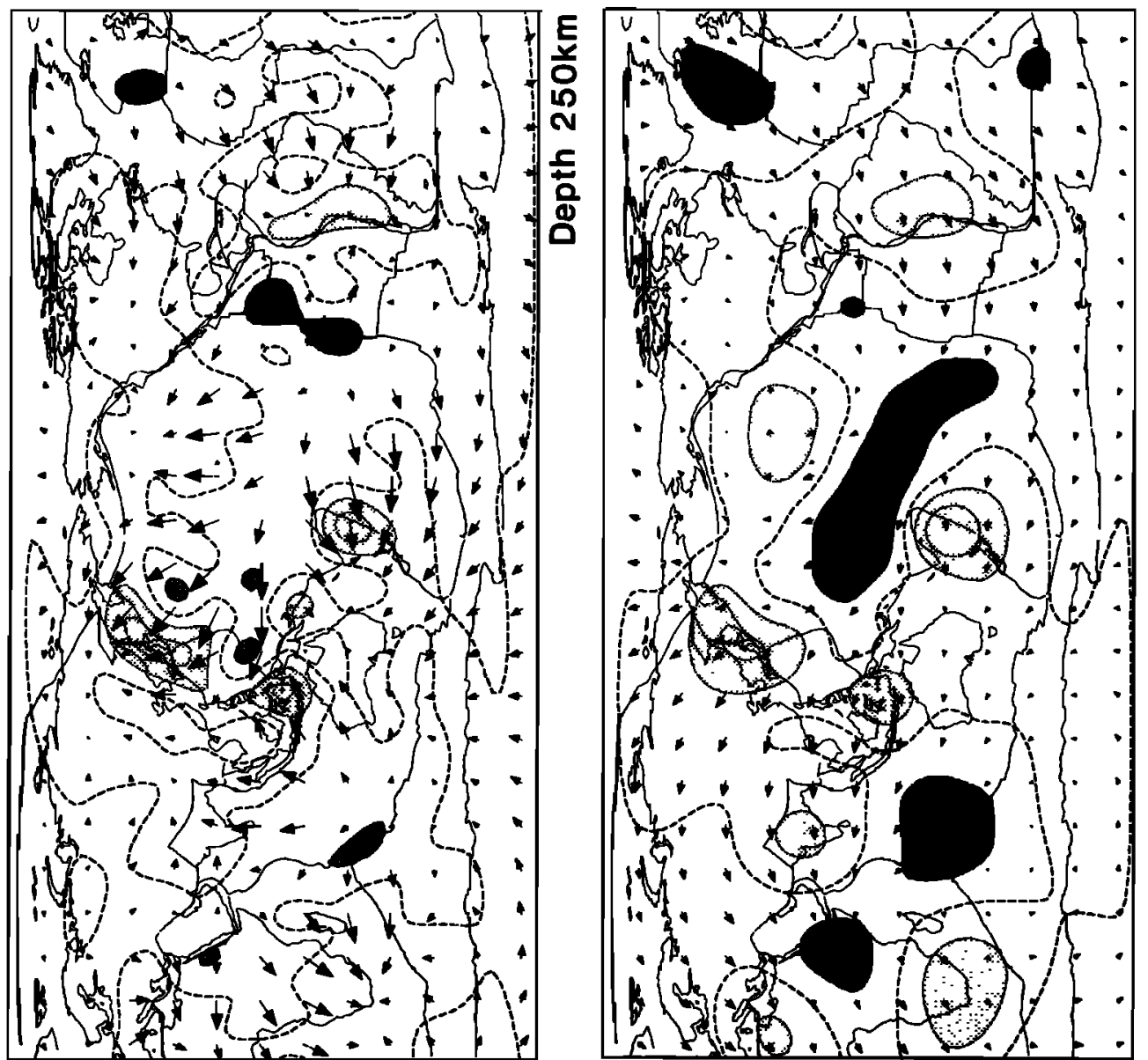

席这它.

安要密

要

궁

居. 웜

论

$\vec{\sigma} \vec{x}$

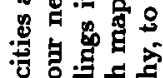

․ㅗ웡

政

5

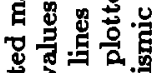

点言皆

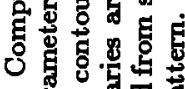

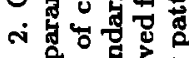

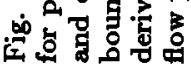


produced by very strong anomalies with low seismic velocity beneath the Red Sea and western Indian Ocean area, that is, by a large volume of buoyant material in the upper mantle which leads to very rapid seafloor spreading both in the Red Sea and along the Carlsberg ridge in the Indian Ocean. Another shortcoming is the quasi-absence of a shear zone along the Pacific coast of North America. This indicates that the model does not include enough negative buoyant material beneath the Aleoutian trench. Let us finally mention that according to seismic tomography a very larger volume of buoyant material is present, both in upper and lower mantle below the central Pacific. The resulting upwelling circulation does not influence the motion of the Pacific plate, its location being away from the plate boundaries. It is, however, the source of the main geoid maximum which happens to be located in that equatorial region. It could also yield an explanation for a broad topography anomaly on that ocean floor [Cazenave et al., 1989]. However the nature of this anomalous bathymetry has been questioned, as it also could be explained by shallower processes. The latter include basaltic floods found in drill holes as well as heat input by small-scale asthenospheric convection which raises the old oceanic lithosphere [Colin and Fleitout, 1990].

In order to visualize the mantle circulation generated in the model of Ricard and Vigny [1989], we have computed in Figure 2 a set of maps at four different depths $(250,650$, 1250 , and $2900 \mathrm{~km}$ ). The arrows depict the horizontal component of the convection currents induced by internal loading, whereas the shadings depict the intensities of the vertical component. One notices the already mentioned major upwelling below the central Pacific and also the one beneath the Red Sea area. Other zones of vigorous upward or downward material circulation can be seen in these maps, as well as horizontal return flow currents in connection with the sur- face plate motion shown in Figure 1. This mantle circulation generates radial and horizontal stresses in the overlying lithospheric plates, which will now be presented, in addition to those due to varying crustal thickness.

\section{STATIC AND DyNamically INDUCEd STREsSes}

The mathematical formulation of the physics linking lateral mass heterogeneities to lithospheric stresses will not be repeated here. First, we have to compute the static response of a lithospheric shell containing mass heterogeneities [Fleitout and Froidevaux, 1982, 1983]. For that only the variations of the Moho depth have been taken into account, the largest one being the contrast between continental and oceanic domains. All thermal variations like those supporting the oceanic ridge topography or some elevated continental regions are assumed to be present in the sublithospheric mantle and shall therefore be encountered in the coming dynamical analysis. The computation is limited to spherical harmonic degrees smaller or equal to 15 . Therefore one always expects a situation of complete compensation and the perturbation of the average vertical stress is $\sigma_{z z}=g M / L$, where $L$ is the lithospheric reference thickness, fixed at 100 $\mathbf{k m}$, and $M$ is the dipolar mass moment built by the excess topography $\Delta m$ and the mass defect $-\Delta m$ corresponding to the crustal root. For simplicity, we loaded the lithosphere with defect masses located at $50 \mathrm{~km}$ depth. This yields value of the dipolar moment $M$ equal to $\Delta m L / 2$. The computed map of deviatoric stresses generated by these loads is found in Figure 3. On this global scale one finds a similar pattern as that existing for Tibet with respect to its low topography and thinner crust surroundings. Here the elevated continental domains are in extension, and the oceanic depressions with their shallower Moho are all in compression. The directions of the principal horizontal deviatoric stress orienta-

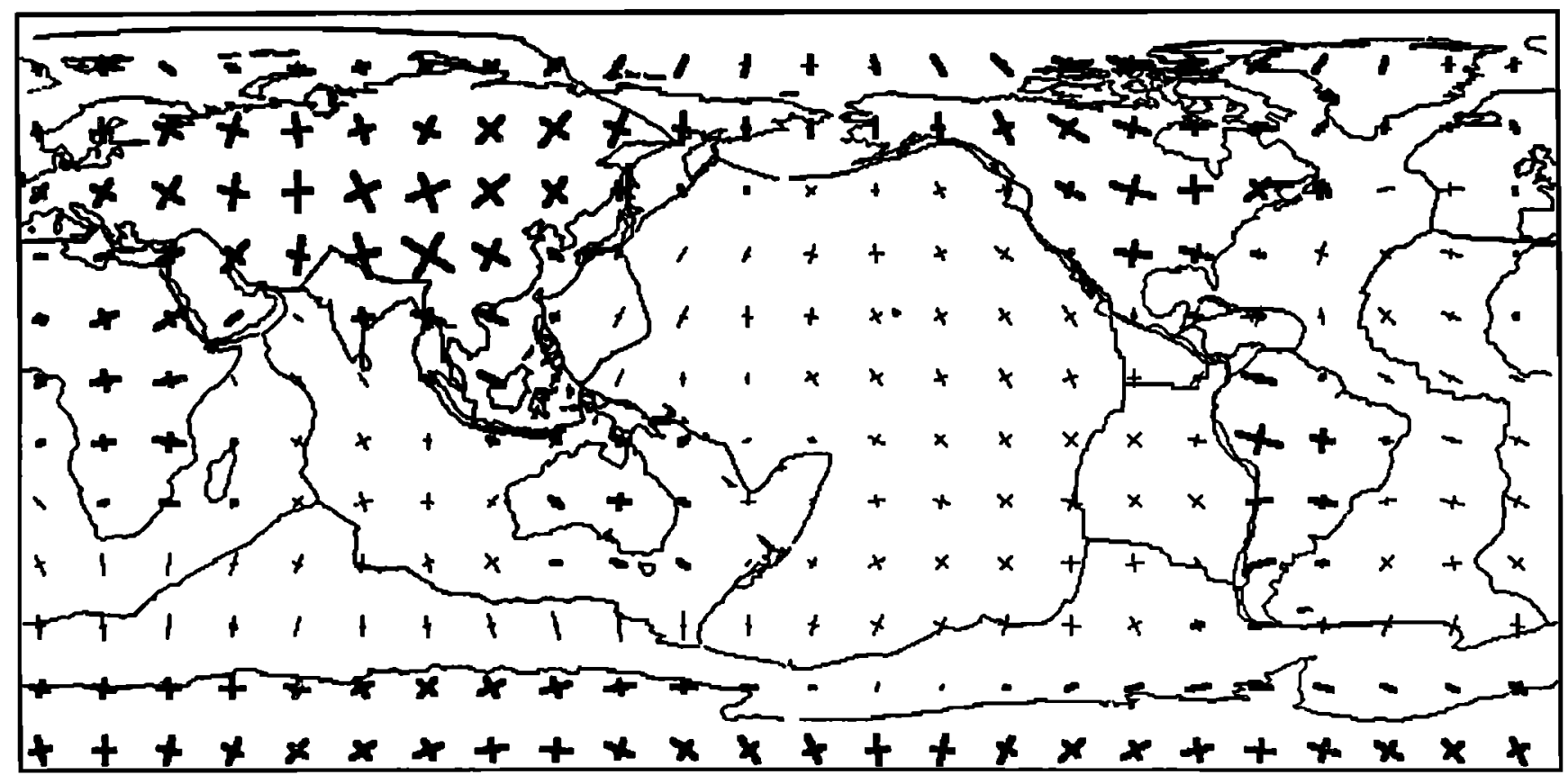

SCALE : $\quad-1000$ bar

Fig. 3. Computed principal deviatoric stress axis in a continuous single elastic shell generated by variations of crustal thicknesses expanded up to degree $l=15$. The thick bars refer to extension; the thin ones refer to compression. 

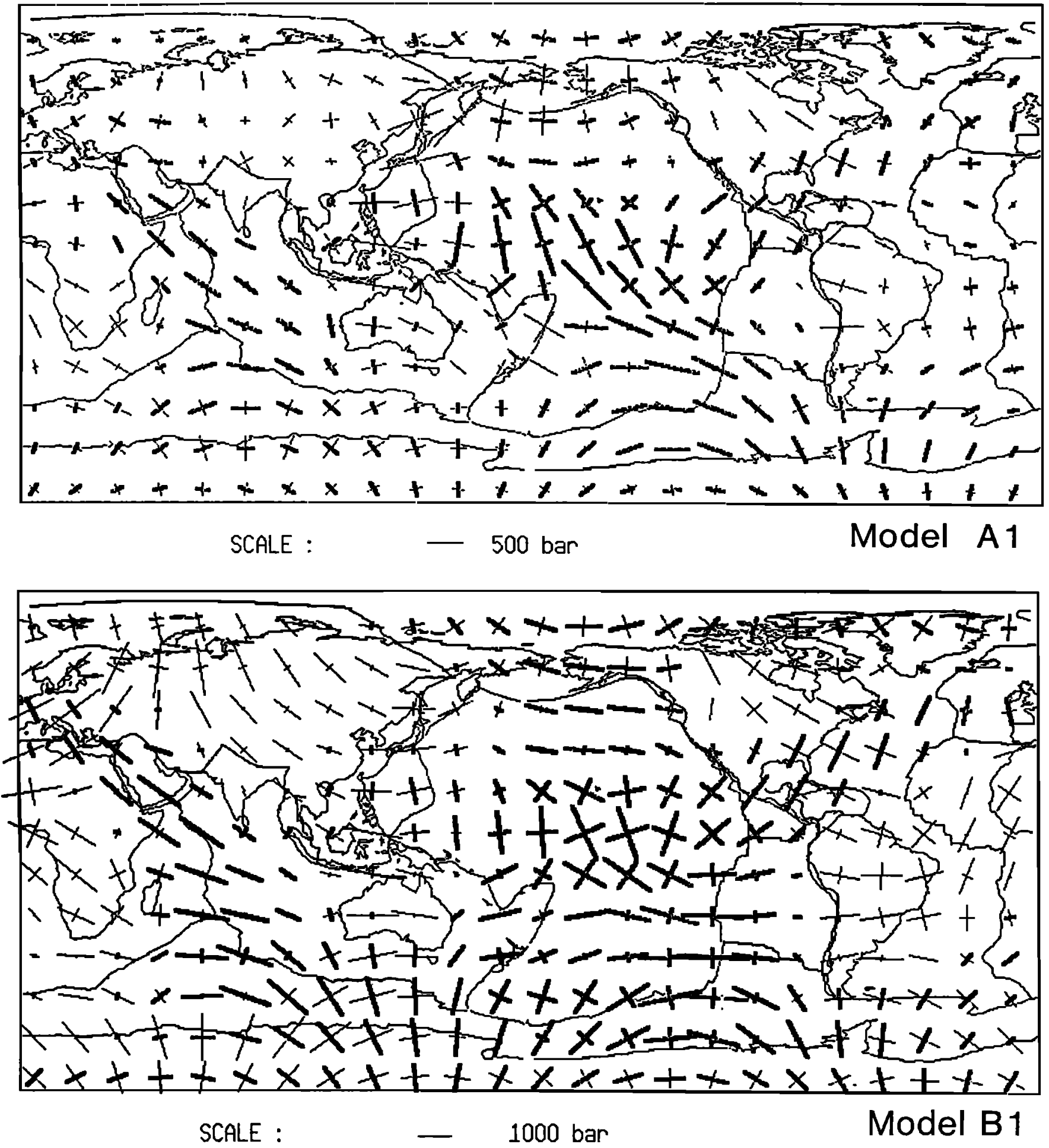

Fig. 4. Computed stress pattern generated in a single continuous lithospheric shell by the model mantle curculation generated by internal loading. Model A contains the same internal loads, which are derived from seismic tomography and oceanic slabs as the model which yielded the induced convection depicted in Figures 1 and 2. For model B the intensity of upper mantle loads has been increased by a factor 6 as explained in the text. The symbols for the principal deviatoric axis are the same as in the previous Figure. Notice that two thick bars refer to tectonic extension, two thin bars refer to compression, and a combination of a thin and a thick bar refers to predominant strike-slip deformation of the lithosphere. The scales for stress intensity in both maps differ by a factor 2.

tions are depicted by thin (compression) or thick (extension) bars. Notice that in the middle of large land masses like Asia or the Pacific plate these stresses are quite isotropic. Their amplitudes are certainly overestimated because of the high value of our compensation depth.
The dynamic Earth model with 11 freely moving plates and internal loads forcing the mantle circulation, which generated the computed plate velocities and deep circulation depicted in Figures 1 and 2, will now be used for the determination of induced intraplate stresses. The physics of 
this model and its mathematical formulation on the basis of Navier-Stokes equations are fully described by Ricard et al. [1984] and Ricard and Vigny [1989]. This approach generalizes earlier studies by Hager and $O^{\prime}$ Connell [1981]. The internal loads are derived from seismic tomography models [Dziewonski, 1984; Woodhouse and Dziewonski, 1984], to which mass heterogeneities corresponding to the subducting oceanic slabs defined by seismicity have been added. These slabs are not mechanically attached to the oceanic plates, but like other density heterogeneities, they contribute to the forcing of the global mantle circulation. There are no direct interplate interactions. The interaction between plates, in particular a resistance to convergence or divergence at corresponding boundaries, are achieved indirectly: an imposed injection or extraction of mantle material creates an appropriate mantle drag beneath the plate edges. By construction the net torque of the basal shear stresses acting below a given plate vanishes. The basal shear and radial stresses derived from the circulation depicted in Figure 2 will now be taken in order to compute the internal state of stress of each plate. All physical quantities are again expressed by means of spherical harmonics up to degree 15. The well-established mechanical theory for elastic shells of finite thickness yields the plate deviatoric stresses [Love, 1944]. Their principal average values will be depicted graphically by means of horizontal principal axes.

The model parameters are the same as those used by $R i$ card and Vigny [1989], that is, a viscosity of $2.6 \times 10^{20} \mathrm{~Pa} \mathrm{~s}$ for the upper mantle and $1.3 \times 10^{22} \mathrm{~Pa} \mathrm{~s}$ for the lower mantle, scaling factors expressed in $\mathrm{km} \mathrm{s}^{-1} / \mathrm{g} \mathrm{cm}^{-3}$ relating velocity anomalies to mass heterogeneities $\delta V_{s} / \delta \rho=30$ in the upper mantle and $\delta V_{p} / \delta \rho=6$ in the lower mantle, and a standard slab excess mass relative to the asthenosphere. This mass amounts to $10^{7} \mathrm{~kg} \mathrm{~m} \mathrm{~m}^{-2}$ and is in agreement with isostasy, that is with the observed topography variation between ridges and older ocean floors. The above value of $\delta V_{s} / \delta \rho$ deliberately damps the upper mantle density anomalies and differs by a factor about 6 from experimental results obtained by changing the temperature of rock samples. The reduced value used here assumes that upper mantle velocity anomalies may have a lithological rather than a thermal origin, without corresponding density variations. This first type of choice will yield solutions called model A. A second model, called B, will also be tested for which this derivative takes the value of $5 \mathrm{~km} \mathrm{~s}^{-1} / \mathrm{g} \mathrm{cm}^{-3}$, i.e. where the seismic velocity variations are assumed to be essentially of thermal origin and the corresponding upper mantle internal loads are relatively important. The stress patterns for the two models will be displayed on Figures 4-6 with labels A and B.

Figure 4 depicts the stresses induced by both model mantle circulations in a continuous lithospheric shell which is not allowed to move. There is some similarity between both results, but please notice the factor 2 in scale for the stress magnitudes. Model B1 has larger stresses because its upper mantle loads are 6 times more intense than for model A1. This enhances particularly the upwellings beneath the Red Sea and Indian Ocean ridge and the resulting extensive stresses. The change is less marked in the central Pacific as the buoyancy sources beneath it are also located in the lower mantle which is unchanged. Model B1 also exhibits a stronger compression for all continents, as the fast seismic velocities found in the subcrustal layers are yielding much denser anomalies than in model A1. Hence the enhanced downwelling tendency. These denser lithospheres could have been included in the static model for intralithospheric loading used to calculate Figure 3. They would have predicted the same compressive tendency which should be added to the extensional contribution associated with the light continental crust.

Figure 5 corresponds to the dynamic Earth models with freely moving lithospheric plates. By comparison with Figure 4, one notices that the fact of these plates being now in motion (model A2 corresponds to Figure 1, bottom map) does not change the main characteristics of the stress pattern. Why is that so? Because the average value of the driving shear stresses is much smaller than the difference between extreme values. The same is true for the resistive stresses opposed to the plate motion. For plate models submitted to edge forces, this would mean that local pushes or pulls are much more intense than the average driving force, for example.

Finally, we have to consider that the global lithospheric stresses derive both from density heterogeneities within the lithosphere and from the dynamic coupling with the convective circulation beneath it. Thus, the stress field of Figure 3 must be added to that of Figure 5 (model A2 or B2). The combined stress patterns are depicted in Figure 6. The resulting model A3 still exhibits a predominantly extensive stress field in most continental areas, whereas model B3 has produced either predominant compression or strike-slip in the same areas, which may be closer to reality. The vigorous upwelling of mantle material dominates the nature of the stress field in the central Pacific. The same remains true around the Red Sea. These extensional anomalies are difficult to compare with the scarce data base, but one may doubt of their reality as they do not correlate with any marked sismicity.

\section{CONCLUDING REMARKS}

The aim of the above physical model and computations was to demonstrate that thanks to seismic tomography data, the mantle convection pattern in today's Earth can now be approached in a realistic manner. Therefore the geoid, the plate velocities and the lithospheric stresses can in principle be predicted and compared with observations, at least as far as the first harmonic degrees of these patterns are concerned.

If the predicted plate velocities in Figure 1 correlate with the plate tectonic picture so well, it is first because the shape of the plates has been defined a priori. This geometry imposes the coherence within each plate and localizes the active boundaries but not their nature. Second, the kinematic pattern is satisfactory because the sign and distribution of internal loads given by seismology turn out to be appropriate.

The computed geoid, for models without or with plates, correlates with the observed one at low spherical harmonics only [Richards and Hager, 1984; Ricard et al., 1989] (see also a qualitative approach by Pavoni [1985]). Its power spectrum decreasing rapidly with degree $l$, its general shape is nevertheless well predicted. Here one should realize that models based on the Dziewonski [1984] tomography seem to lack a strong enough $(l=2, m=0)$ term for the induced geoid. This component of the mantle circulation would therefore also be missing and affect our stress pattern.

Plate velocities, surface topography, geoid, and tectonic stresses are all related to lateral density variations within. 

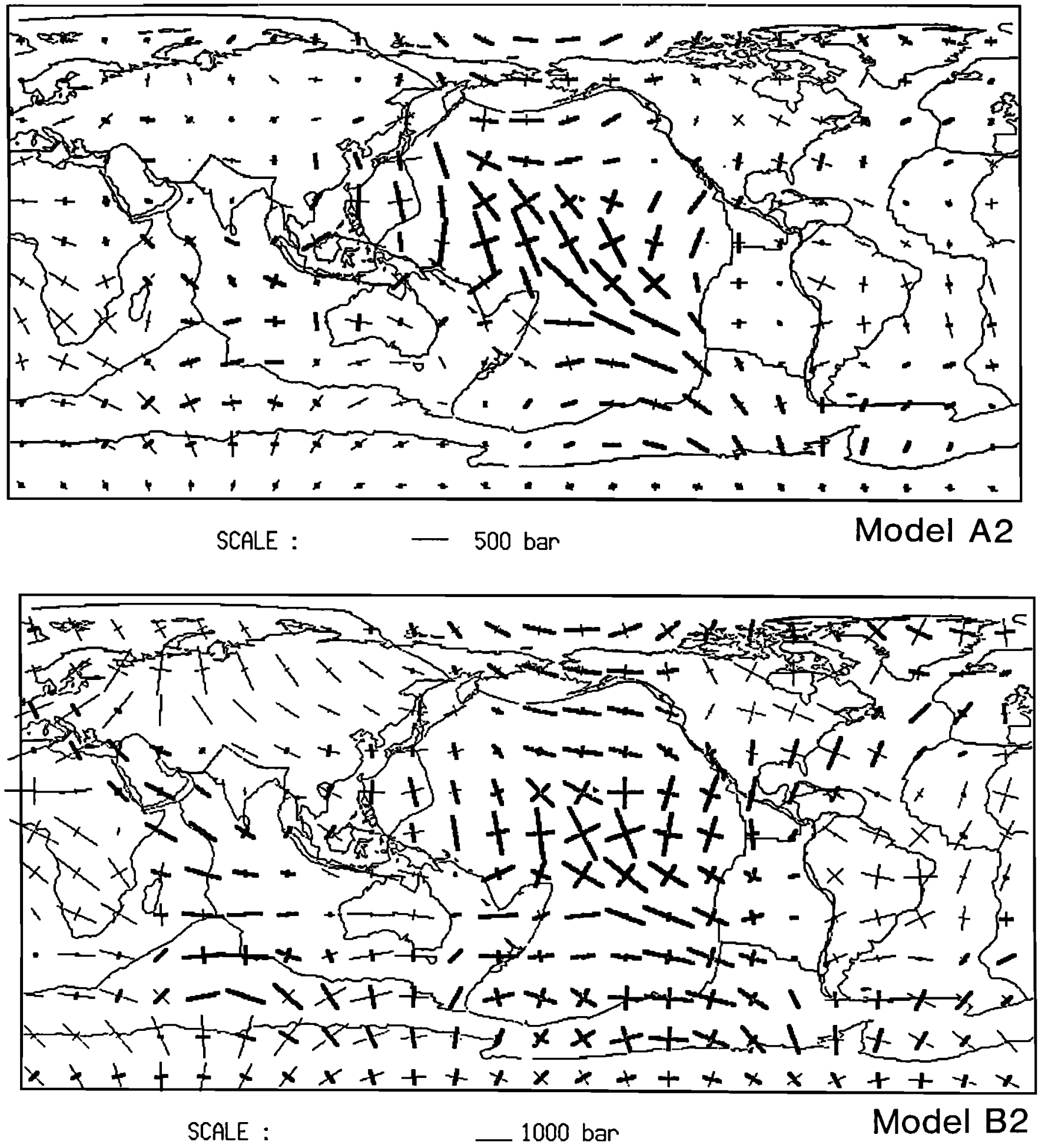

Fig. 5. Same as Figure 4 but with a mantle circulation found when the elastic lithosphere is subdivided in 11 freely moving plates with boundaries as indicated in all maps shown here but expressed in the frame work of a spherical harmonic expansion up to $l=15$.

the Earth [Runcorn, 1963]. A global model built in order to predict lithospheric stresses must also be tested on its capability to predict plate motion and geoid. A successful geoid prediction already reflects some understanding of the stress field, at least of its radial component. A good plate motion model also insures some reasonable representation of the horizontal stresses. However, these two tests can be satisfied for more than one viscosity structure of the model Earth. Each structure yields a different stress field solution and different induced topographies at the surface, and other internal interfaces with changes in density. A better control of these topographies would help select the best solutions. In our introduction we mentioned that the observations are often ambiguous, as is the case for the anomalous topogra- 


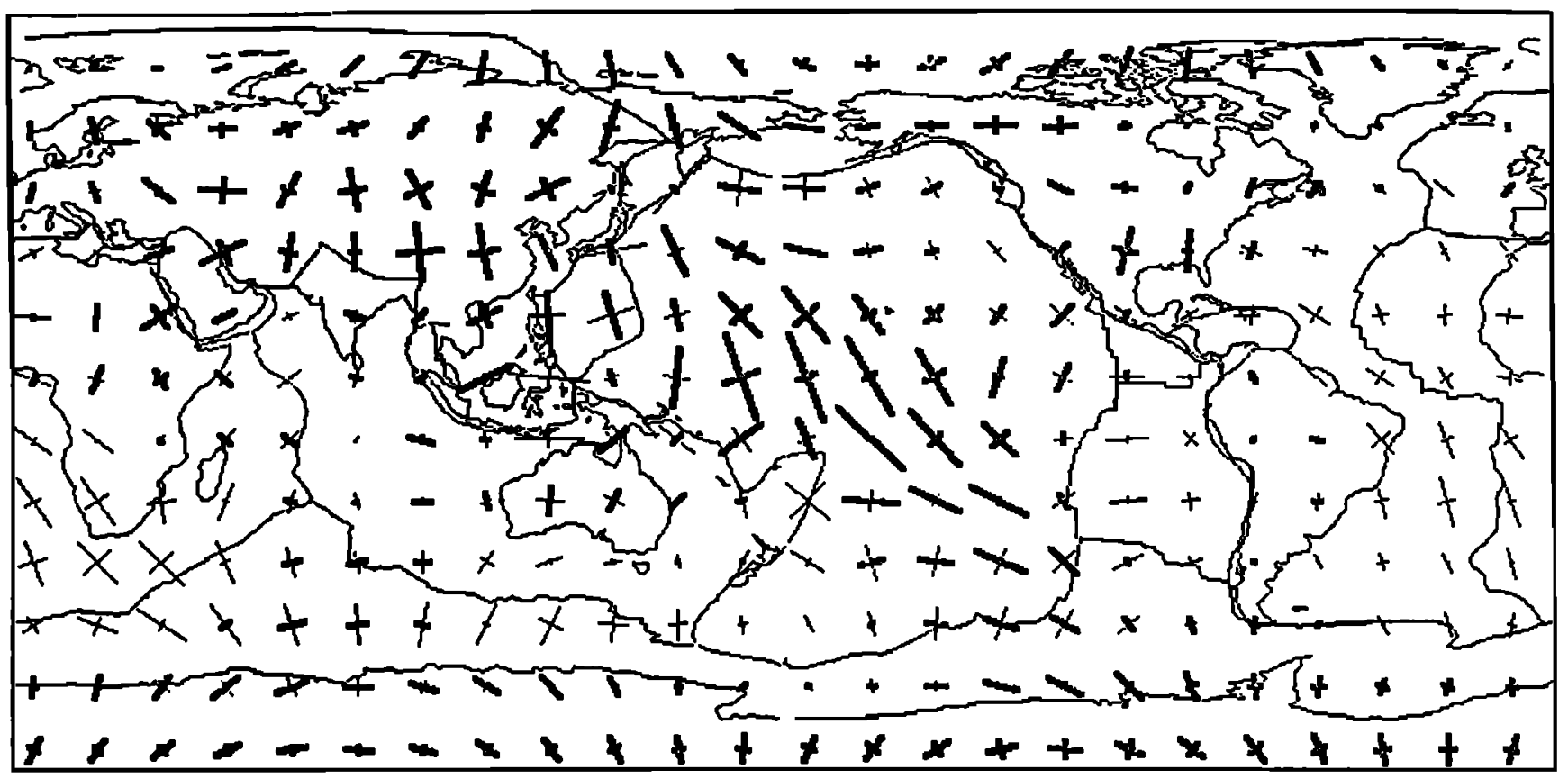

SCALE :

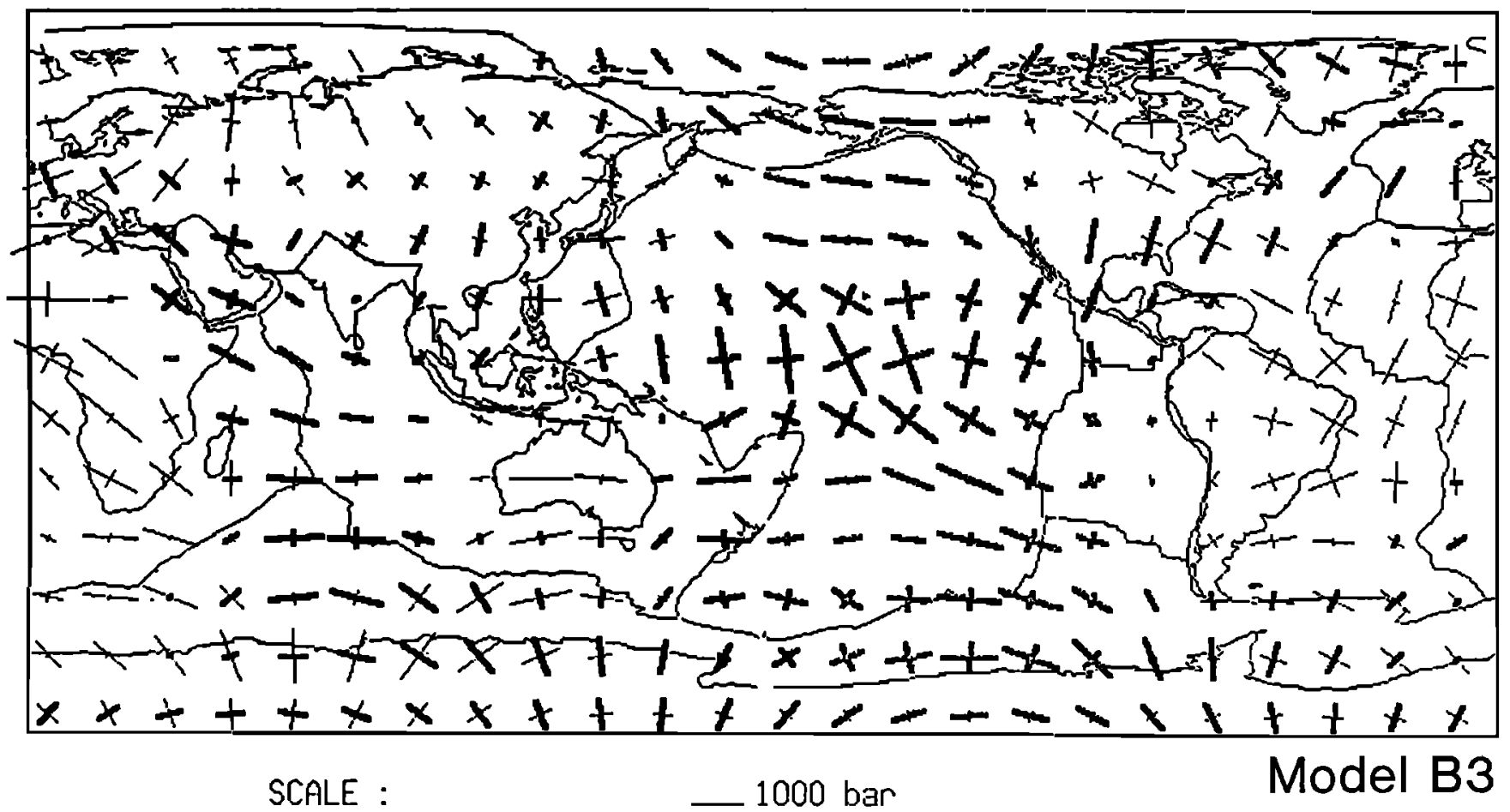

Fig. 6. Combination of the deviatoric stresses caused by variations in crustal thickness on the one hand and by basal shear coupling with the mantle circulation on the other hand. These maps imply a superposition of the stress patterns depicted in Figures 3 and 5.

phy that might correlate with the main geoid high in the western Pacific. As an example, one knows that two-layer convection models generate topography at $650 \mathrm{~km}$ depth, but less stresses at the Earth's surface.

The predicted stresses are dominated by the same low harmonic degrees as the computed geoid. Therefore one should not look for significant variations at wavelengths shorter than $5000 \mathrm{~km}$, except for those generated by crustal anoma- lies for which one may come down to $2500 \mathrm{~km}$. Shorterwavelength variations like Tibet and the Altiplano can, of course, not be resolved in these models. Neither can one expect a precise picture of the extensional belt along oceanic ridges. However, "ridge push" sources are present at shallow depth in the tomography, and the computed plate velocities are indeed divergent at ridges in Figure 1.

The retrieval of the low degree stress pattern from the 
existing data set [Zoback et al., 1989] is probably impossible. Only the orientation and sign of the principal axis are known, not their magnitude. Furthermore, the coverage is somewhat restricted to deformation belts. Thus the understanding of tectonic processes is sofar better documented on a regional than on a global scale. Comparison of these first stress models with global data is therefore premature. Nevertheless, they suggest that stresses acting at the base of the lithosphere may not be dominated by the direction of plate velocities, because other large-scale convective mode must exist.

One major problem encountered in this first attempt to relate lithospheric stresses to the density heterogeneity sources at all mantle depths lies in choosing the proper relationship between observed seismic velocities and density values. This was illustrated by taking two values of $\delta V_{s} / \delta \rho$ for the upper mantle. A longer term problem will be to separate lithological from temperature effects in order to remove possible spurious density variations in particular in the upper mantle. It now seems that seismic models including anisotropic wave propagation [Montagnier and Tanimoto, 1991] or attenuation [Roult et al., 1990] change the tomography results, e.g., by removing part of the Red Sea anomaly.

In conclusions, our discussion explains why uncertainties in the model parameters and scarcity and non-completeness of the data base prevent useful comparisons on a global scale. The situation improves rapidly. For regional studies the static equilibrium approach with plate boundary forces and intraplate sources remains useful. Dynamic coupling with vigorous convection beneath the plates should, however, not be ignored now that their magnitude seems to begin to be quantified.

\section{REFERENCES}

Artyushkov, E. V., Stresses in the lithosphere caused by crustal thickness inhornogeneities, J. Geophys. Res., 78, 7675-7708, 1973.

Cazenave, A., A. Souriau, and K. Dominh, Global coupling of Earth surface topography with hotspots, geoid and mantle heterogeneities, Nature, 340, 54-57, 1989.

Cloetingh, S., and R. Wortel, Stress in the Indo-A ustralian plate, Tectonophysics, 132, 49-67, 1986.

Cloetingh, S., R. Wortel, and N. J. Vlaar, On the initiation of subduction zones, Pure Appl. Geophys. 129, 7-29, 1989.

Colin, P., and L. Fleitout, Topography of the ocean floor: Thermal evolution of the lithosphere and interaction of deep mantle heterogeneities with the lithosphere, Geophys. Res. Lett., 17, 1961-1964, 1990.

Dziewonski, A.M., Mapping the lower mantle: determination of lateral heterogeneity in $P$ velocity up to degree and order $6, J$. Geophys. Res., 89, 5929-5952, 1984.

Fleitout, L., and C. Froidevaux, Tectonics and topography for a lithosphere containing density heterogeneities, Tectonics, 1 , 21-57, 1982.

Fleitout, L., and C. Froidevaux, Tectonic stresses in the lithosphere, Tectonics, 2, 315-324, 1983.

Forsyth, D., and S. Uyeda, On the relative importance of the driving forces of plate motion, Geophys. J. R. Astron. Soc., 43, 163-200, 1975.

Forte, A. M., and W. R. Peltier, Plate tectonics and aspheroidal Earth structure: the importance of poloidal-toroidal coupling, J. Geophys. Res., 92, 3645-3679, 1987.

Froidevaux, C., and B. L. Isacks, The mechanical state of the lithosphere in the Altiplano-Puna segment of the Andes, Earth Planet. Sci. Lett., 71, 305-314, 1984.

Hager, B. H., Oceanic plate motions driven by lithospheric thickening and subducted slabs, Nature, 276, 156-159, 1978.
Hager, B. H., and R. J. O'Connell, A simple global model of plate dynamics and mantle convection, J. Geophys. Res., 86, 4843-4867, 1981.

Hager, B. H., R. W. Clayton, M. A. Richards, R. P. Comer, and A. M. Dziewonski, Lower mantle heterogeneity, dynamic topography, and the geoid, Nature, 313, 541-545, 1985.

Isacks, B., and P. Molnar, Distribution of stresses in the descending lithosphere from a global survey of focal mechanism solutions of mantle earthquakes, Rev. Geophys., 9, 103-174, 1971.

Lliboutry, L., The driving mechanism, its source of energy and its evolution studied with a three-layer model, J. Geophys. Res., 77, 3759-3770, 1972.

Love, A. E. A., A Treatise on the Mathematical Theory of Elasticity, Dover, New York, 1944.

McKenzie, D., and C. Bowin, The relationship between bathymetry and gravity in the Atlantic Ocean, J. Geophys. Res., 81 , 1903-1915, 1976.

Montagner, J.P., and T. Tanimoto, Global upper mantle tomography of seismic velocities and anisotropies, J. Geophys. Res., in press, 1991.

Nataf, H.C., I. Nakanishi, and D. L. Anderson, Measurements of mantle wave velocities and inversion for lateral heterogeneities and anisotropy, J. Geophys. Res., 91, 7261-7307, 1986.

Parsons, B., and F. M. Richter, Mantle convection and the oceanic lithosphere, Sea, 7, 73-117, 1981.

Pavoni, N., Die pazifisch-antipazifisch Bipolarität im Strukturbild der Erde und ihre geodynamische Deutung, Geol. Rundsch., $74,251-266,1985$.

Ricard, Y., and C. Vigny, Mantle dynamics with induced plate tectonics, J. Geophys. Res., 94, 17,543-17,559, 1989.

Ricard, Y., L. Fleitout, and C. Froidevaux, Geoid heights and lithospheric stresses for a dynamic Earth, Ann. Geophys., 2, 267-286, 1984 .

Ricard, Y., C. Vigny, and C. Froidevaux, Mantle heterogeneities, geoid and plate motion: A Monte Carlo inversion, J. Geophys. Res., 94, 13,739-13,754, 1989.

Richards, M. A., and B. H. Hager, Geoid anomaly in a dynamic Earth, J. Geophys. Res., 89, 5987-6002, 1984.

Richardson, R. M., S. C. Solomon and N. H. Sleep, Tectonic stress in the plates, Rev. Geophys., 17, 981-1020, 1979.

Roult, G., B. Romanowicz, and J.-P. Montagnier, 3-D upper mantle shear velocity and attenuation from fundamental mode free oscillation data, Geophys. J. Int., in press, 1990.

Runcorn, S. K., Satellite gravity measurements and the laminar viscous flow model of the Earth's mantle, J. Geophys. Res., 69, 4389-4394, 1963.

Vigny, C., Y. Ricard, and C. Froidevaux, The driving mechanism of plate tectonics, Tectonophysics, 187, 345-360, 1991.

Vilotte, J-P., M. Madariaga, M. Daignières, and $O$. Inkiewicz, Numerical study of continental collision: influence of buoyancy forces and an initial stiff inclusion, Geophys. J. R. Astron. Soc., 84, 279-310, 1986.

Vlaar, N. J., and M. J. R. Wortel, Lithospheric aging, instability and subduction, Tectonophysics, 32, 331-351, 1976.

Woodhouse, J. H., and A. M. Dziewonski, Mapping the upper mantle: Three-dimentional modeling of Earth structure by inversion of seismic waveforms, J. Geophys. Res., 89, 5953-5986, 1984.

Zoback, M. L., et al., Global patterns of tectonic stresses, Nature, 341, 291-298, 1989.

Bai W., Laboratory of Geophysics, Academia Sinica, Beijing, People's Republic of China.

C. Froidevaux, Y. Ricard, and C. Vigny, Département de Géologie, Ecole Normale Supérieure, 24, rue Lhomond, 75231 Paris Cedex 05, France.

(Received December 19, 1989; revised October 12, 1990; accepted December 19, 1990.) 